\title{
0260 OLDER ADULT PEDESTRIAN INJURIES IN THE UNITED STATES: WHAT ARE THE LEADING CAUSES AND HOW BIG IS THE PROBLEM?
}

R B Naumann, A M Dellinger*, T Haileyesus, G Ryan Correspondence: Division of Unintentional Injury Prevention, National Center for Injury Prevention and Control, Centers for Disease Control and Prevention (CDC), 4770 Buford Hwy, N.E. Mailstop F-62 Atlanta, GA 30341, USA

10.1136/ip.2010.029215.260

Background As the US population ages, more older adults will face transportation and mobility challenges. This study examines the characteristics and number of non-fatally injured older pedestrians.

Methods Data were obtained from the National Electronic Injury Surveillance System All Injury Program (NEISS-AIP) for the years 2001 through 2006. Cases included persons aged 65 years and older who were non-fatally injured on a public roadway by falling, being hit by a motor vehicle, overexerting themselves, being struck by an object or animal, or being hit by some other form of transport.

Results Each year, an estimated 52482 older adults were treated in emergency departments for non-fatal pedestrian 


\section{IP Safety 2010 abstracts}

injuries. Falling and being hit by a motor vehicle resulted in $92.5 \%$ of older adult pedestrian injuries. Older adult pedestrian injuries were often severe; about a third of injuries were to the head or neck, nearly a third resulted in a fracture, and $16 \%$ resulted in hospitalisation or transfer to another facility. Nearly a quarter of, or more than 9000 , older pedestrian fallrelated injuries involved a curb.

Conclusions The growth in the older adult population could add to the overall burden of these non-fatal pedestrian injuries, including negatively affecting the health and quality of life of older adults and further taxing the already strained US healthcare system. Making transportation and mobility improvements, including environmental modifications, is important to preventing these injuries. Modifications may include medians, refuge islands and curb modifications. 